Original Article

\title{
Phytochemical Screening and Antimicrobial Activity of Ziziphus spina-christi Stem Barks
}

\author{
Abdelrafie M. Makhawi, Mujahed I. Mustafa* and Hajer A. Uagoub \\ Department of Biotechnology, University of Bahri, Khartoum, Sudan. \\ *Corresponding author: Mujahed I. Mustafa; mujahedimustafa@gmail.com
}

\begin{abstract}
This study was carried out in Khartoum State, during December 2017 The plant of Ziziphus spina-christi belong to family Rhamnaceae and locally known as Cedar, it was chosen for this study because of its using traditionally in treatment of many diseases. Microwave-assisted extraction (MAE) approach had been used to the dried sample at $170^{\circ} \mathrm{C}$ to reduce both time and extraction solvent volume, and to decrease the damage of bioactive compounds without extending the period of extraction. $20 \mathrm{~g}$ of sample was soaked with Petroleum ether, Ethyl-acetate, ethanol, methanol and distilled water for 72 hour. The extracts were concentrated using rotary evaporator at $40^{\circ} \mathrm{C}$ and were stored at $4^{\circ} \mathrm{C}$. The phytochemical screening were carried out on different extracts of Ziziphus spina-christi stem bark and they showed to contain high amount of Tannins (4+ in all extracts), moderate amount of flavonoids and Triterpenes, trace amount of coumarins and Alkaloids and high amount of Saponins, Anthraquinones and Cardiac glycosides. The antimicrobial activity of extracts were evaluated against four standard bacteria species (gram positive; Bacillus subtilis, Staphylococcus aureus) and (gram negative; Escherichia coli, Pseudomonas aeruginosa; in addition of one standard fungi (Candida albicans). The results of antimicrobial tests indicated that the methanolic extract inhibited the growth of all microorganisms and most extracts showed several points of antimicrobial activity. These findings act as platform to assist in cure of bacterial and fungal infections.
\end{abstract}

Keywords: Ziziphus spina-christi stem barks, antimicrobial activity, crude extracts, phytochemical screening, zone of inhibition. 


\section{Introduction:}

Medicinal Plants have been attaining great recognition all over the globe.[1, 2] They act as a very crucial therapeutic agents as well as valuable raw active compounds for manufacturing many traditional and modern treatments[3].

World Health Organization (WHO) recently reported that, there is an unprecedented increase in the occurrence of multidrug-resistant (MDR) infections worldwide [4, 5]. Currently, efforts are being focused to propose new drugs to multidrug resistant bacterial strains. Natural products, especially those obtained from medicinal plants, have demonstrated to be remarkable compounds with exceptional properties, such as rupturing the membrane of bacteria, enzymes activity inhibition and bacterial biofilm formation, which making them perfect applicants for these MDR bacteria[6-11].

Ziziphus Spina-christi is wide spread in tropical and subtropical region. The genus Ziziphus Spina-christi is widely distributed in the Middle East. Since ages extracts of Ziziphus spina christi have been used as inflammatory treat toothache, analgesic, pectoral, astringent (LF), antirheumatic, purgative (FR), for stomach pain ,anti-helminthic[12-14].

Escherichia coli is the main cause of infant mortality and diarrheal diseases. In the severe cases of diarrhea, the patient may have bloody diarrhea and can become life threatening. E. coli also responsible for urinary tract infection has become resistant to the drug that has been used to cure it $[15,16]$. Staphylococcus aureus is resistant to antibiotics such as penicillin and methicillin; Staphylococcus aureus can cause life-threatening diseases such as sepsis and endocarditis; [17, 18] therefore, biochemical screening studies provide a promising alternative for drugs production from secondary metabolites of medicinal Plants due to its fewer side effects and cheaper cost.

This study focuses on determination of the chemical components and biochemical screening of Ziziphus spina-christi stems bark and to verify its antibacterial and antifungal activities.

\section{Materials and Methods}

\subsection{Sample Collection}

Fresh sample of Ziziphus spina-christi stem barks were collected from ALGAZIRA ISLANG, Northern of Omdurman, Khartoum State. The samples were washed and dried in open air in shade for two weeks. 


\subsection{Plants extract Protocols:}

Different extracts were prepared according to Robinson method [19] with little methodology development, as described: Microwave-assisted extraction (MAE) approach had been used to the dried sample at $170^{\circ} \mathrm{C}$ to reduce both time and extraction solvent volume, and to decrease the damage of bioactive compounds without increasing the period of extraction.[20] Twenty grams of sample was sopping with Petroleum ether, Ethyl-acetate, ethanol and methanol for 72 hours. The extracts were concentrated using rotary evaporator at $40^{\circ} \mathrm{C}$, and finally the dried extracts were store at $4^{\circ} \mathrm{C}$.

\subsection{Preparation of aqueous extract:}

Fine powder $(100 \mathrm{gm})$ was poured with distilled water $(300 \mathrm{ml})$ and left for 24 hours at room temperature. The mother liquor was filtered. The filtrate was vaporized till it reached dryness state; the residue thus obtained was the aqueous plant extract. All extracts were stored under aseptic conditions in bottles at $20^{\circ} \mathrm{C}$.

\subsection{Phytochemical screening:}

\subsubsection{Test of alkaloids:}

A $3 \mathrm{ml}$ of extract was pour on petri dish and dried in water path, then dissolved in $10 \mathrm{ml}$ of $\mathrm{HCL}$ $2 \%$ OR $\mathrm{NH} 4 \mathrm{OH} 10 \%$ and transferred in three test-tube, each one contain $1 \mathrm{ml}$, few drops of Dragendorff's reagent were added into each tube (Dragendorff's give orange precipitate. Wagner's give reddish precipitate and Hager's give yellow precipitate) which indicate the present of Alkaloids.

\subsubsection{Test of Flavonoids:}

A $2 \mathrm{ml}$ of extract evaporated on petri dish and then $10 \mathrm{ml}$ of ethanol were added, then transferred into four tests tube, the one added $1 \mathrm{ml}$ of $\mathrm{NaOH}$ that give yellow color, the second test tube $\mathrm{Mg}$ powder were added followed by 1 drop of $\mathrm{H}_{2} \mathrm{SO}_{4}$ put in water path. The formation of a pink, crimson red which indicate the present of Flavonoids, the third test tube $\mathrm{AlCl}_{3}$ were added the formation of creamsh color indicated the present of Flavonoid, then ammonium solution were added the fourth test tubes. The formation of yellow/orange color indicated the present of Flavonoid. 


\subsubsection{Test of Triterpenes and sterols:}

A $2 \mathrm{ml}$ of extract was dried in water path and dissolved in $6 \mathrm{ml}$ of chloroform, a few drops of concentrated sulfuric acid were added along the side of the test tube two layers was formed ,the upper green color indicated the presence of sterol, and the lower red brown ring indicated the presence of triterpenes.

\subsubsection{Test of Tannins:}

A $2 \mathrm{ml}$ of extract poured in petri dish and late to dry, then was dissolved in $10 \mathrm{ml}$ ethanol solution and divided into two test tubes, the one $0.5 \mathrm{ml}$ of ferric chloride was added the formation of blue dark color indicator the presence of tannins, the second $0.5 \mathrm{ml}$ of gelatin salt (10\%) was added, the formation of white precipitate point to the presence of tannins.

\subsubsection{Test of Saponins:}

$0.5 \mathrm{ml}$ of extract was poured in test tube, $10 \mathrm{ml}$ of distilled water were added, the tube was strongly shaken for 30 seconds. The tube was allowed to stand and observed for creation of foam, which persisted for an hour, was taken as evidence for subsistence of saponins.

\subsubsection{Test of Coumarins:}

A $1 \mathrm{~g}$ of plant powder was soaked in $10 \mathrm{ml}$ distilled water in test tube and filter paper attached to the test tube to be saturated with the vapor after spot of $0.5 \mathrm{~N}$ of potassium hydroxide put on it, then the filter paper was examined under Ultra Violet (UV) light, the presence of coumarins was designated if the spot have found to be adsorbed the UV light.

\subsubsection{Test of Cardiac glycosides:}

A $0.1 \mathrm{~g}$ of plant powder was soaked in $1 \mathrm{ml}$ glacial acetic acid with one drop of ferric chloride solution, $1 \mathrm{ml}$ the sulphuric acid was added under layer, a brown ring obtained was indicated the presence of glycosides.

\subsubsection{Test of Anthraquinones:}

A $0.1 \mathrm{~g}$ of plant powder was dissolved in $1 \mathrm{ml}$ water and $5 \mathrm{ml}$ of chloroform was added and shacked for 5 minutes, after shaking two layer were formed, the chloroform layer was separated. 
$1 \mathrm{ml}$ of ammonia solution (10\%) was added into $1 \mathrm{ml}$ of chloroform the appearance of pink or red or violet color designates the presence of Anthraquinones.

\subsection{Microbial analysis:}

Table (1): National Collection of Type Culture (NCTC), Colindale, England:

\begin{tabular}{ccc}
\hline Name of standard organism & ATCC code & Type of organism \\
\hline Escherichia coli (E. c) & 25922 & Gram negative bacteria \\
Pseudomonas aeruginosa (P. a) & 27853 & Gram negative bacteria \\
Bacillus subtilis (B. s) & 8236 & Gram positive bacteria \\
Staphylococcus aureus (S. a) & 25923 & Gram positive bacteria \\
Candida albicans & 7596 & Fungi \\
\hline
\end{tabular}

(ATCC): American Type Culture Collection Rockville, Maryland, USA.

\subsubsection{Preparation of Standard Microorganism's Suspensions:}

Preserved bacterial strains (obtained from the Department of Microbiology, University of Bahri, Khartoum, Sudan) were cultured on nutrient broth. Full loop of bacteria was inoculated in nutrient broth at $37^{\circ} \mathrm{C}$ in incubator for 24 hours; the growth was observed in the broth, and then sub-cultured to nutrient agar plates for 24 hours. When growth confirmed as the correct species by examining it under a light microscope (DM3000; Germany), the individual colonies were again sub-cultured to nutrient agar slopes and inoculated at $37^{\circ} \mathrm{C}$ in incubator until the growth occurred. $1 \mathrm{ml}$ of the bacteria suspension was diluted with $9 \mathrm{ml}$ of sterile saline that was taken with pipette and shaken gently to produce a suspension that containing about (10 -10 CFU/ml). The suspension was stored in the refrigerator at $4^{\circ} \mathrm{C}$ till used. Preserved fungal strains were cultured on Saboraud dextrose agar, prior to antifungal susceptibility screening [21].

\subsubsection{Extracts analysis for antimicrobial activity:}

The method used to test the sensitivity to the plant extract, as outlined by the International Commission on Microbiological Specifications for Foods [22]. $0.1 \mathrm{ml}$ of a broth culture of each bacterium (Escherichia coli, Staphylococcus aureus, Bacillus subtilus and_Pseudomonas aeruginosa) and fungi (Candida albicans) was inoculated on 
each plate. Wells were done under aseptic conditions. Each well was filled with $20 \mu \mathrm{l}$ of stem bark extract of Ziziphus spina -christi of different solvents at different concentrations $(100,50,25 \mu \mathrm{g} / \mathrm{ml})$, then plates were cooled for 2 hours to allow proper diffusion before incubation at $37^{\circ} \mathrm{C}$ for 48 hours. After incubation, the inoculated sensitivity plates were removed from the incubator and inhibition zones around the wells were measured. An inhibition zone measuring more than $14 \mathrm{~mm}$ was considered sensitive.[23]

\section{Results:}

\subsection{Results of extraction and physical properties:}

Five solvents were used in successive polarities to extract secondary metabolites from Ziziphus spina-christi stem barks and their properties.

The results of the extractive values of Ziziphus spina-christi as following: for methanol $4.43 \%$ (crystal bright black), followed by ethanol $4.4 \%$ (crystal bright black), ethyl acetate $2.885 \%$ (brown powder), petroleum ether $1.9 \%$ (brown crust fine powder), and distilled water $3.85 \%$ (brown powder). The extraction results and fractionation yields are shown in (Table 1).

Table (2): Properties and extractive value of Ziziphus spina-christi stem barks:

\begin{tabular}{lllll}
\hline Solvents of extraction & Characteristic & Color & Weight $(\mathrm{g})$ & Yields $(\%)$ \\
\hline Methanol & crystal & Bright black & 8.86 & 4.43 \\
Ethanol & crystal & Bright black & 8.8 & 4.4 \\
Ethyl acetate & powder & brown & 5.77 & 2.885 \\
Petroleum ether & Crust of fine powder & brown & 3.8 & 1.9 \\
Distilled water & powder & brown & 7.7 & 3.85 \\
\hline
\end{tabular}

\subsection{Phytochemical screening activity of Ziziphus spina -christi stems barks}

Phytochemicals analysis carried out on the Ziziphus spina -christi stems barks extracts unmasked the presence of bioactive compounds, which qualitatively analyzed and presented in (Table 2). 
Table (3): Shows phytochemical screening results of Ziziphus spina-christi stem barks:

\begin{tabular}{|c|c|c|c|c|c|}
\hline Test/ Solvent & Methanol & Petroleum ether & $\begin{array}{l}\text { Distilled } \\
\text { water }\end{array}$ & $\begin{array}{l}\text { Ethyl } \\
\text { acetate }\end{array}$ & Ethanol \\
\hline $\mathrm{NaOH}$ & +++ & ++ & ++ & ++ & +++ \\
\hline $\mathrm{AlCl} 3$ & +++ & + & + & ++ & +++ \\
\hline $\mathrm{NH} 4 \mathrm{OH}$ & +++ & + & ++ & ++ & ++ \\
\hline $\mathrm{Mg} / \mathrm{H} 2 \mathrm{SO} 4$ & ++++ & + & +++ & ++ & ++++ \\
\hline Tannin Ferric chloride & ++++ & ++++ & ++++ & ++++ & ++++ \\
\hline Gelatin & ++++ & ++++ & ++++ & ++++ & ++++ \\
\hline Wagner's & + & + & + & + & ++ \\
\hline Dragendorff's & + & + & ++ & + & ++ \\
\hline Hager's & +++ & + & ++ & +++ & +++ \\
\hline Lieberman & ++ & ++ & + & ++ & ++ \\
\hline Salkowski & +++ & +++ & ++++ & +++ & +++ \\
\hline Coumarins KOH/UV & + & - & + & ++ & + \\
\hline Saponins Foam test & ++++ & + & ++ & + & ++++ \\
\hline Anthraquinones & ++++ & + & + & ++++ & ++++ \\
\hline Cardiac glycoside & ++++ & ++++ & +++ & ++++ & +++ \\
\hline
\end{tabular}

$(++++)$ : high amount, (+++): moderate amount, $(++)$ : low amount, $(+)$ : trace amount, $(-)$ : not found.

\subsection{Antimicrobial tests}

The extracts of Ziziphus spina -christi stem bark at concentrations $(100 \mathrm{mg} / \mathrm{ml}, 50 \mathrm{mg} / \mathrm{ml}$, $25 \mathrm{mg} / \mathrm{ml}$ ), were subjected to antimicrobial tests by using cup plate agar diffusion method and inhibition zone were measured in ( $\mathrm{mm}$ ) against four bacterial strains and one fungi.(Table 1) The range of inhibition was found 14-25 $\mathrm{mm}$. 
Table (4): results of antimicrobial activities of Ziziphus spina-christi stem barks:

\begin{tabular}{ccccccc}
\hline Extract & Concentration & C.a & B.s & S.a & P.a & E.c \\
\hline Methanol & 100 & 20 & 25 & 21 & 24 & 22 \\
& 50 & 18 & 22 & 20 & 23 & 21 \\
Ethanol & 25 & 17 & 20 & 18 & 19 & 20 \\
& 100 & 20 & 22 & 21 & 19 & 20 \\
Ethyl acetate & 50 & 18 & 20 & 20 & 17 & 18 \\
& 25 & 15 & 18 & 18 & 16 & 17 \\
Distilled water & 100 & 17 & 22 & - & 15 & 18 \\
& 50 & 16 & 20 & - & 14 & 17 \\
Petroleum ether & 100 & 15 & 18 & - & - & 15 \\
& 50 & 17 & 24 & 18 & 20 & 20 \\
& 25 & 16 & 20 & 16 & 17 & 18 \\
& 100 & & & & & 17 \\
\hline
\end{tabular}

B.s: Bacillus subtilis; S.a: Staphyllococcus aureus; E.c, Escherichia coli; P.a: Pseudomonas aeruginosa; C.a: Candida albicans; concentration of extracts $0.2 \mathrm{ml} / \mathrm{cup}(100,50,25 \mathrm{mg} / \mathrm{ml})$.

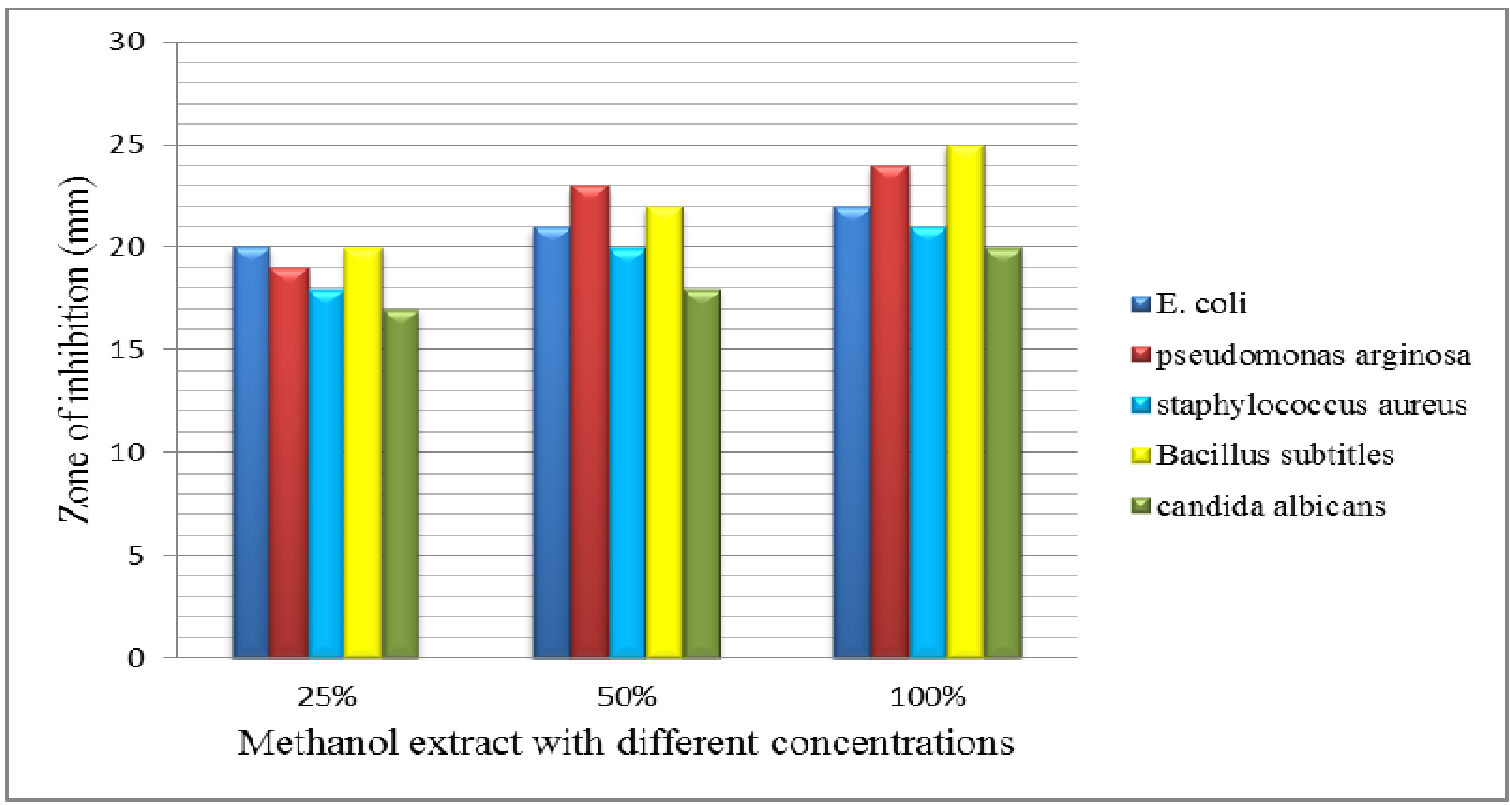

Figure (1): Inhibition Zone $(\mathrm{mm})$ of bacterial and fungal pathogens by stem barks extract of Ziziphus spina-christi. 


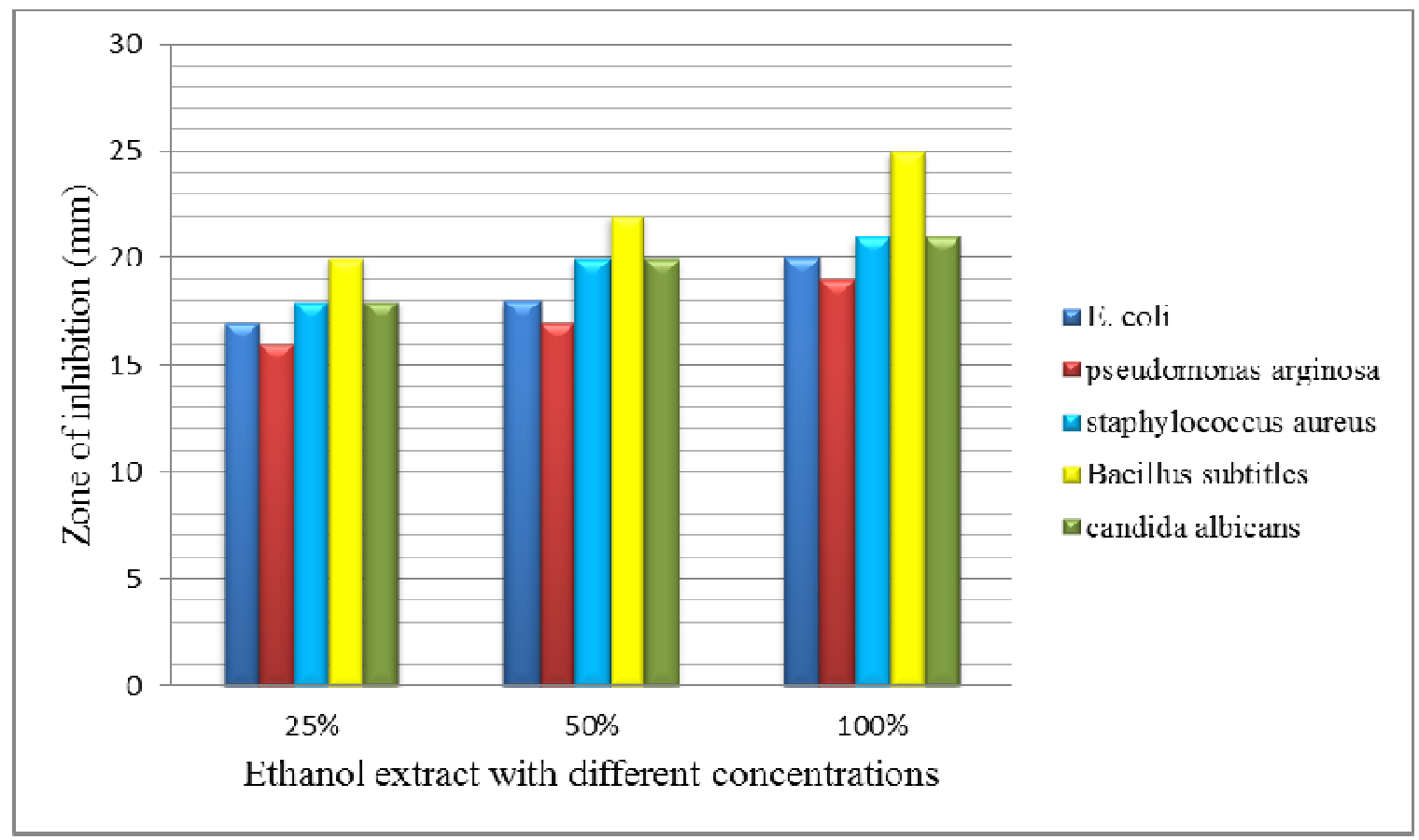

Figure (2): Inhibition Zone (mm) of bacterial and fungal pathogens by stem barks extract of Ziziphus spina-christi.

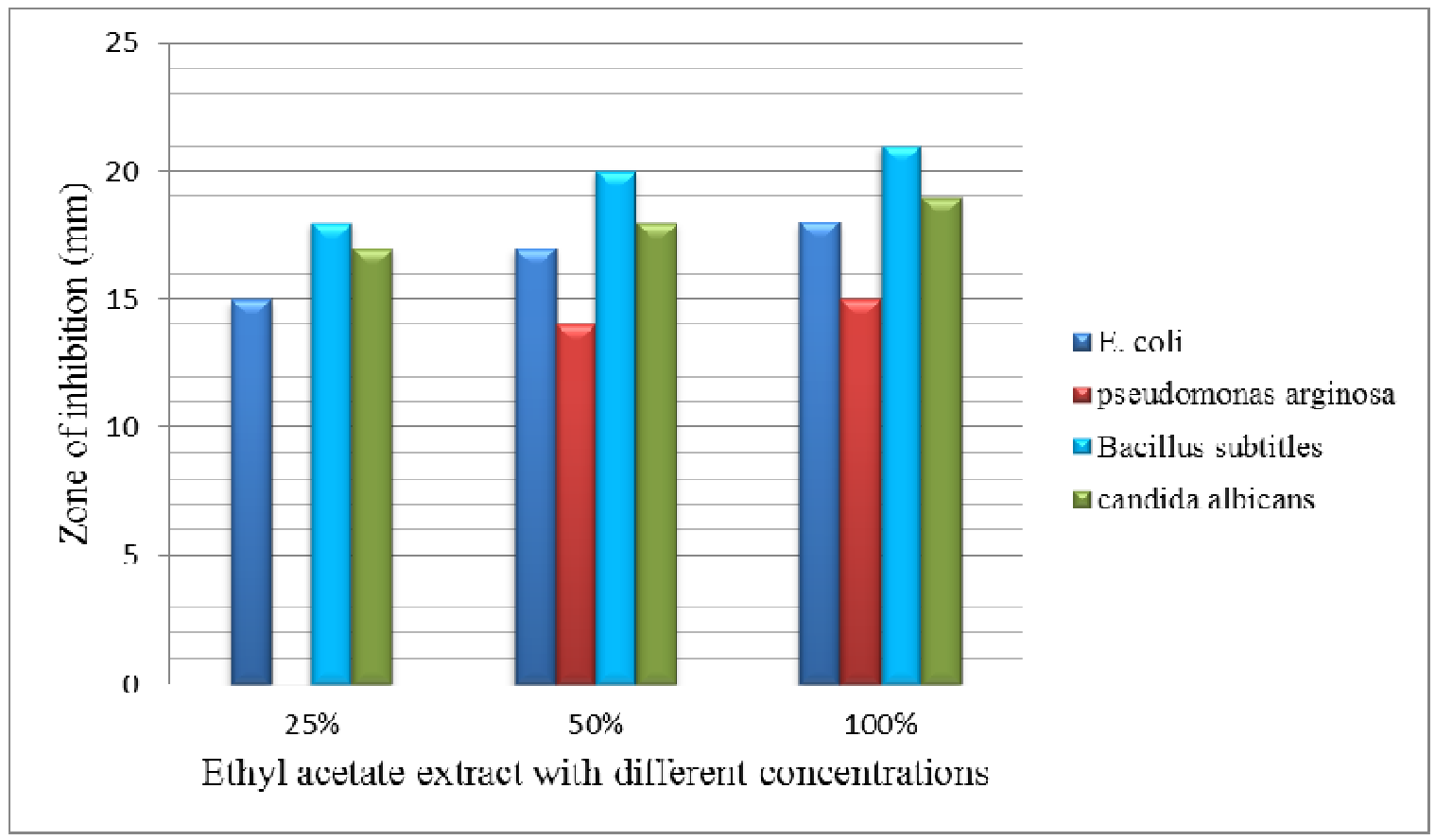

Figure (3): Inhibition Zone (mm) of bacterial and fungal pathogens by stem barks extract of Ziziphus spina-christi. 


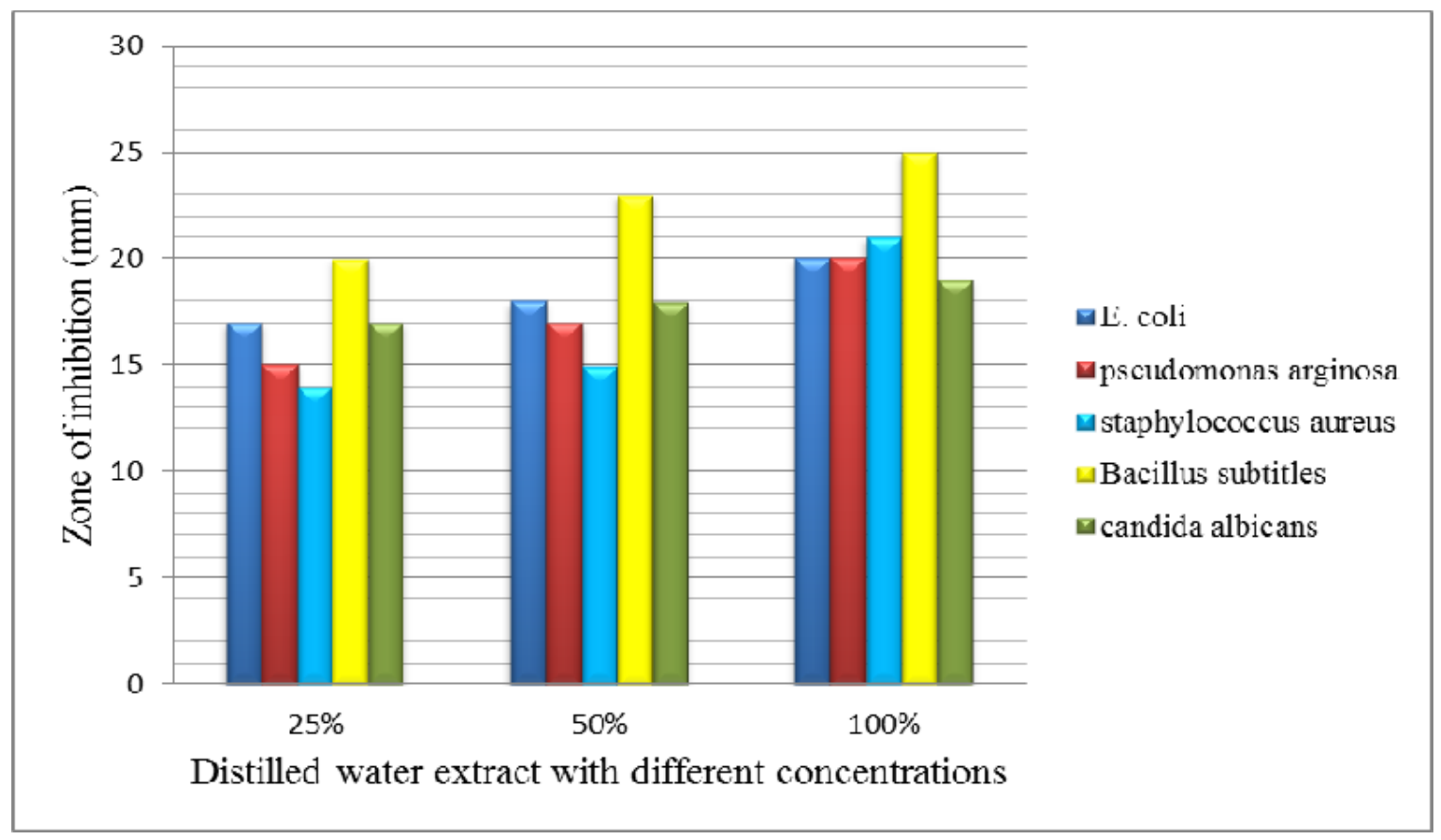

Figure (4): Inhibition Zone (mm) of bacterial and fungal pathogens by stem barks extract of Ziziphus spina-christi.

\section{Discussion:}

Sudan is the largest country in Africa with rich plants due to the climate diversity which are used in traditional medicine to treat several diseases.[24-26] In the present study, five solvents were used in successive extractable method from Ziziphus spina-christi stem barks, methanol solvent gave generally higher extractability than those obtain from (ethanol, ethyl acetate, distilled water and petroleum ether) (Table 2). In case of ethyl acetate, distilled water the consistency of extractable material seem to be brown powder, with differences in yield, and the extract of ethanol and methanol seem to be crystal bright black with differences in yield. Petroleum ether it is lower extractability than all other it is crust of fine brown powder. Variation was observed in the colors of extracts may be were reflection to type of solvent ingredients' of plant.

Phytochemical screening of chemical constituents of Ziziphus spina-christi stem bark extracts, were found that all with high amount of tannins. The flavonoids were present in moderate amount in methanol and ethanol extracts. Moreover, all extracts found contain low amount of coumarins; while alkaloids present in low amount in ethanol. triturbin and sterol present in moderate amount in all extracts. In addition cardic glycoside was found in a high amount in all extracts. Extracts 
showed to contain high amount of Saponins. The extracts showed to contain high amount of anthraquinones;(Table 3) all act as antioxidants, as well known, antioxidants decrease free radical attack on DNA and therefore prevent mutations that cause cancer;[27] this difference may due to the condition of the experiments or well as in differences in methodology, or/and in variation of amount of secondary metabolites. In contrast synthetic antioxidants have recently been shown to cause critical health issues such as liver damage, due to their carcinogenicity effect. Hence, the development of safer antioxidants from natural sources has been recognized, and medicinal plants have been used as a reliable source of alternative medicines to treat various diseases.[28]

The methanol showed high activity at all concentrations $(100 \%, 50 \%, 25 \%)$, against the clinical isolation of E. coli $(22,21,20)$ respectively, as well as against of Pseudomonas arginosa $(24,23,19)$, Staphylococcus aureus $(21,20,18)$, and showed low activity against Candida albicans $(20,18.17)$, and showed high activity against Bacillus subtitles $(25,22,20)$ (Figure 1). Ethanol was showed against these bacteria: E. coli $(20,18,17)$, pseudomonas arginosa $(19,17,16)$, Staphylococcus aureus (21,20,18), and showed as high amount against Bacillus subtitles (22,20,18), and at low amount against Candida albicans $(20,18,15)$.The ethyl acetate extracts high activity against Bacillus subtitles (22, 20, 18), and low activity against Candida albicans (17, 16, 15), E. coli (18,17,15), Pseudomonas arginosa (15, 14, ND), and have no any activity against Staphylococcus aureus. Distilled water showed high activity against Bacillus subtitles (24,23,20), and low activity against Candida albicans (18,17,16), Staphylococcus aureus(18,16,14), Pseudomonas arginosa (20,17,15), Staphylococcus aureus(16,15,14), (Figure 4) while petroleum-ether has no inhibition zone against all tested microorganisms (Table 4).

This compared with assays reported by El-kamali and Mahjoub[29] methanol extract of Ziziphus spina-christi stem bark was found effective against all tested Gram negative and Gram positive bacteria inhibition zone (range between 20-30 mm). Ethanol extract of Ziziphus spina-christi stem barks was found effective against all tested bacteria except Escherichia coli. Where Ethyl acetate of Ziziphus spina-christi stem barks was active against both Gram positive and Gram negative bacteria. Aqueous extract of Ziziphus spina-christi stem barks was moderately active against Gram positive and Gram negative bacteria inhibition zone (range between 15-17 mm). Petroleum ether extract of Ziziphus spina-christi stem bark had the ability to inhibit Bacillus subtilis $(15 \mathrm{~mm})$ and Escherichia coli $(20 \mathrm{~mm})$. 
Our findings can be used to enhance the potential of currently used antimicrobial agents.[30]

Further studies needed to ensure the safety of Ziziphus spina -christi stem bark and development of safer antioxidants from this natural source.

\section{Conclusion:}

The presented results offer supporting evidence for effective use of selected plant extracts. Antimicrobial resistance is reported to be on the increase due to gene Mutation of the disease pathogens. Ziziphus spina $\square$ Christi was chosen For this study because of their reputation in folklore medicine as antimicrobial agents and usage of different parts in many diseases. Phytochemical screening was carried out and lead to presence of some Secondary metabolites the plant was showed to contain alkaloids, flavonoids, tannins, triterpenes, coumarins, saponins, cardic glycoside, anthraquinone, all act as antioxidants. The crude extracts were subjected to antimicrobial assays using cup Plate diffusion method and the inhibition zone were measured in $\mathrm{mm}$. The methanol extracts of Ziziphus spina-christi gave good results activities against bacterial and fungal organisms were used, while the petroleum showed absence of inhibition zone against four bacterial and on fungal used.

\section{Data Availability:}

The data which support our findings in this study are available from the corresponding author upon reasonable request.

\section{References:}

[1] L. C. Tapsell, I. Hemphill, L. Cobiac, C. S. Patch, D. R. Sullivan, M. Fenech, et al., "Health benefits of herbs and spices: the past, the present, the future," Med J Aust, vol. 185, pp. S1-s24, Aug 212006.

[2] F. Jamshidi-Kia, Z. Lorigooini, and H. Amini-Khoei, "Medicinal plants: Past history and future perspective," Journal of HerbMed Pharmacology, vol. 7, pp. 1-7, 01/01 2018.

[3] N. Bamola, P. Verma, and C. Negi, "A Review on Some Traditional Medicinal Plants," International Journal of Life-Sciences Scientific Research, vol. 4, 01/01 2018.

[4] M. Mendelson and M. P. Matsoso, "The World Health Organization Global Action Plan for antimicrobial resistance," S Afr Med J, vol. 105, p. 325, Apr 62015.

[5] M. Unemo, M. M. Lahra, M. Cole, P. Galarza, F. Ndowa, I. Martin, et al., "World Health Organization Global Gonococcal Antimicrobial Surveillance Program (WHO GASP): review of new data and evidence to inform international collaborative actions and research efforts," Sex Health, Aug 232019.

[6] M. Mulat, A. Pandita, and F. Khan, "Medicinal Plant Compounds for Combating the Multi-drug Resistant Pathogenic Bacteria: A Review," Curr Pharm Biotechnol, vol. 20, pp. 183-196, 2019. 
[7] S. Khatri, M. Kumar, N. Phougat, R. Chaudhary, and A. K. Chhillar, "Perspectives on Phytochemicals as Antibacterial Agents: An Outstanding Contribution to Modern Therapeutics," Mini Rev Med Chem, vol. 16, pp. 290-308, 2016.

[8] R. Barbieri, E. Coppo, A. Marchese, M. Daglia, E. Sobarzo-Sanchez, S. F. Nabavi, et al., "Phytochemicals for human disease: An update on plant-derived compounds antibacterial activity," Microbiol Res, vol. 196, pp. 44-68, Mar 2017.

[9] M. Ayaz, F. Ullah, A. Sadiq, F. Ullah, M. Ovais, J. Ahmed, et al., "Synergistic interactions of phytochemicals with antimicrobial agents: Potential strategy to counteract drug resistance," Chem Biol Interact, vol. 308, pp. 294-303, Aug 12019.

[10] J. Shin, V.S. Prabhakaran, and K. S. Kim, "The multi-faceted potential of plant-derived metabolites as antimicrobial agents against multidrug-resistant pathogens, "Microb Pathog, vol. 116, pp. 209-214, Mar 2018.

[11] A. Borges, M. J. Saavedra, and M. Simoes, "Insights on antimicrobial resistance, biofilms and the use of phytochemicals as new antimicrobial agents," Curr Med Chem, vol. 22, pp. 2590-614, 2015.

[12] T. Tounekti, M. Mahdhi, and H. Khemira, "Ethnobotanical Study of Indigenous Medicinal Plants of Jazan Region, Saudi Arabia," Evid Based Complement Alternat Med, vol. 2019, p. 3190670, 2019.

[13] A. M. Alzahrani, A. A. Alzahrani, and A. A. Alsharm, "The Use of Ziziphus spina-christi Extract in Treating Erlotinib (Tarceva(R)) Associated Rash: A Case Report," Case Rep Oncol, vol. 12, pp. 909-912, Sep-Dec 2019.

[14] R. Shakiba, M. A. Nilforoushzadeh, F. Hashem-Dabaghian, B. Minaii Zangii, A. Ghobadi, L. Shirbeigi, et al., "Effect of Cedar (Ziziphus spina-christi) topical solution in mild to moderate acne vulgaris: a randomized clinical study," J Dermatolog Treat, pp. 1-6, Nov 242019.

[15] Z. D. Blount, "The unexhausted potential of E. coli," Elife, vol. 4, Mar 252015.

[16] E. V. Taylor, T. A. Nguyen, K. D. Machesky, E. Koch, M. J. Sotir, S. R. Bohm, et al., "Multistate outbreak of Escherichia coli 0145 infections associated with romaine lettuce consumption, 2010," J Food Prot, vol. 76, pp. 939-44, Jun 2013.

[17] C. Fuda, M. Suvorov, S. B. Vakulenko, and S. Mobashery, "The basis for resistance to beta-lactam antibiotics by penicillin-binding protein $2 \mathrm{a}$ of methicillin-resistant Staphylococcus aureus," J Biol Chem, vol. 279, pp. 40802-6, Sep 242004.

[18] G. Satta, O. Massidda, and L. D'Andrea, "The mechanism of staphylococci resistance to methicillin: a critical analysis of dominant opinions, "J Chemother, vol. 3 Suppl 1, pp. 144-8, Jan 1991.

[19] T. Robinson, "The Organic Constituents of Higher Plants: Their Chemistry and Interrelationships," SERBIULA (sistema Librum 2.0), vol. 6, 01/01 1963.

[20] S. Tsubaki, M. Sakamoto, and J.-I. Azuma, "Microwave-assisted extraction of phenolic compounds from tea residues under autohydrolytic conditions," Food Chemistry - FOOD CHEM, vol. 123, pp. 1255-1258, 12/01 2010.

[21] T. Ahumuza and C. Kirimuhuzya, "Qualitative (Phytochemical) Analysis and Antifungal Activity of Pentas decora (De Wild), a Plant Used Traditionally to Treat Skin Fungal Infections in Western Uganda," Research in Pharmaceutical Biotechnology Vol. 3(7), pp. 75-84, July 2011, vol. 3, pp. 75-84, 01/01 2011.

[22] "Establishment of microbiological safety criteria for foods in international trade. International Commission on Microbiological Specifications for Foods, "World Health Stat Q, vol. 50, pp. 119-23, 1997. 
[23] I. R. Kubra, P. S. Murthy, and L. J. M. Rao, "In vitro Antifungal Activity of Dehydrozingerone and its Fungitoxic Properties," Journal of Food Science, vol. 78, pp. M64-M69, 2013.

[24] S. S. Bhadoriya, A. Ganeshpurkar, R. P. S. Bhadoriya, S. K. Sahu, and J. R. Patel, "Antidiabetic potential of polyphenolic-rich fraction of Tamarindus indica seed coat in alloxan-induced diabetic rats," J Basic Clin Physiol Pharmacol, vol. 29, pp. 37-45, Jan 26 2018.

[25] W. S. Koko, M. A. Mesaik, R. Ranjitt, M. Galal, and M. I. Choudhary, "Immunosuppressive phenolic compounds from Hydnora abyssinica A. Braun," BMC Complement Altern Med, vol. 15, p. 400, Nov 92015.

[26] G. El Ghazali, M. Tohami, A. Egami, W. Abdalla, and M. Mohammed, Medicinal Plants of the Sudan, part IV, "Medicinal Plants of Northern Kordofan", 1997.

[27] S. J. Duthie, A. Ma, M. A. Ross, and A. R. Collins, "Antioxidant supplementation decreases oxidative DNA damage in human lymphocytes," Cancer Res, vol. 56, pp. 12915, Mar 151996.

[28] J. Javanmardi, C. Stushnoff, E. Locke, and J. M. Vivanco, "Antioxidant activity and total phenolic content of Iranian Ocimum accessions," Food Chemistry, vol. 83, pp. 547-550, 12/01 2003.

[29] H. Hatil, H. El-Kamali, S. Al-Tayeb, and A. Mahjoub, "Antibacterial Activity of Francoeuria crispa, Pulicaria undulata, Ziziphus spina-christi and Cucurbita pepo Against Seven Standard Pathogenic Bacteria," 02/22 2020.

[30] S. Harakeh, I. Khan, S. B. Almasaudi, E. I. Azhar, S. Al-Jaouni, and A. Niedzweicki, "Role of Nutrients and Phyto-compounds in the Modulation of Antimicrobial Resistance," Curr Drug Metab, vol. 18, pp. 858-867, 2017. 